\title{
Rancang Bangun Kunci Pintu Rumah Berbasis Internet of Things (IoT)
}

\author{
Mahendra peratama ${ }^{1}$, Ahmad Syazili ${ }^{2}$ \\ ${ }_{1}^{1}$ Informatics Departement, Bina Darma University, Palembang, Idnonesia \\ ${ }_{2}^{2}$ Information System Departement, Bina Darma University, Palembang, Idnonesia \\ Email: 1mahendraperatama46@gmail.com, 22yazili@binadarma.ac.id
}

\begin{abstract}
One of the problems of theft of goods at home is often caused by our own negligence as homeowners who forget to lock the door of the house when traveling. In addition to the problem of failing to lock the door which makes unknown people enter the house. Forgetting to put the key or worse, we could lose the key to our house, and the key could be found by someone with malicious intent and on us or our family. By utilizing the Internet of Things (IoT), a device is developed that can open and lock the door of the house, so that homeowners no longer have to worry about forgetting to lock the door. Using Nodemcu esp8266 which is already equipped with a wifi module to be able to connect to the internet, and can be controlled via an application on a smartphone via the internet.
\end{abstract}

Keywords: Internet Of Things (IoT), Key, Nodemcu esp8266

\section{PENDAHULUAN}

Teknik Informatika adalah jurusan yang mempelajari bagaimana penerapan logika matematika untuk mengelola informasi yang mencakup transformasi data atau pengolahan fakta melalui simbolik menggunakan teknologi komputer semaksimal mungkin. Seiring kemajuan zaman yang terus berkembang, teknologi juga ikut berkembang hal yang dulu kita anggap mustahil atau tidak mungkin kini bisa kita wujudkan dengan bantuan teknologi. Begitu juga dengan keamanan rumah terutama pintu, apa lagi rumah sebagai tempat untuk menikmati hidup yang nyaman, tempat istirahat, tempat berkumpulnya keluarga, dan tempat pamer status sosial.

Belum lagi di kota-kota besar banyak aktivitas yang harus kita awali di pagi hari dan di lakukan di luar rumah dan seringkali kita lupa mengkunci 


\section{Journal of Computer and Information Systems Ampera}

Vol. 2, No. 1, January 2021 e-ISSN: 2775-2496

https://journal-computing.org/index.php/journal-cisa/index

pintu. Saat menggunakan sistem keamanan pada sebuah pintu, biasanya kita membuka/mengunci pintu secara manual. Kita membutuhkan kunci untuk membuka atau mengunci pintu tersebut. Tentu saja keamanan tidak dapat dijamin. Tentunya jika kita harus membawa kunci kemanapun kita pergi, hal ini sangat bermasalah, apalagi jika kita lupa meletakkan kunci atau bahkan beresiko kehilangan kunci, hal ini dapat menimbulkan masalah lain. Seperti kita sendiri akan sulit mengkunci pintu, dan jika anak kunci tersebut di temukan oleh orang lain bisa saja dia masuk ke dalam rumah dengan mudah dan melakukan aksi kejahatan.

Terus kemajuan teknologi pada era internet saat ini berkembang sangat cepat. Salah satu perkembangan teknologi tersebut adalah Internet of Thing atau yang biasa dikenal dengan istilah IoT. IoT merupakan sebuah teknologi yang digunakan untuk menerima serta mengirim sebuah data dalam jaringan kepada objek tertentu baik itu benda maupun perangkat tanpa disertai dengan interaksi dari manusia dengan manusia maupun manusia dengan computer. Internet of Thing (IoT) memiliki banyak tantangan dalam perkembanganya saat ini. Proses manajemen sistem pada perangkat yang digunakan untuk memantau ketersediaan perangkat IoT yang digunakan untuk memantau sistem sangat diperlukan untuk mengatasi tantangan tersebut. Sistem pemantauan pada perangkat IoT adalah sistem yang digunakan untuk memantau perangkat IoT dari sumber, jaringan, dan perangkat penyimpanan (disk). Oleh karena itu, jika ada masalah atau gangguan pada perangkat, dapat dengan cepat diidentifikasi. Proses mengumpulkan data dan informasi dari sebuah perangkat dilakukan oleh sistem monitoring yang selanjutnya memaksimalkan sumber daya yang dimiliki untuk proses penganalisaanya[1].

Interner of Things juga memiliki tantangan, salah satu tantangan utama Internet of Things adalah untuk menutup kesenjangan antara dunia fisik dan dunia informasi. Misalnya, bagaimana memproses data yang diperoleh dari perangkat elektronik melalui antarmuka antara pengguna dan perangkat. Sensor mengumpulkan data fisik mentah dari adegan waktu nyata dan mengubahnya menjadi format yang dapat dipahami oleh mesin untuk memudahkan pertukaran antara berbagai bentuk format data[2].

Dengan maksud memanfaatkan kemajuan teknologi yang ada saat ini maka sistem kunci pintu elektronik tersebut dapat dibuat dengan gabungan komponen elektronik yaitu mikrokontroler dan aplikasi. 


\section{Journal of Computer and Information Systems Ampera}

Vol. 2, No. 1, January 2021 e-ISSN: 2775-2496

https://journal-computing.org/index.php/journal-cisa/index

Dengan bantuan teknologi ini diharapkan bisa mengurangi rasa takut, tidak yakin sudah mengunci pintu rumah atau belum saat berada di luar dan mengurangi aksi pencurian rumah karena kelalaian kita sendiri yang lupa mengkunci pintu, jadi kita tidak harus kembali ke rumah untuk melakukan pengecekan yang tidak efektif dari sisi waktu dan dapat membuat kita terlambat melakukan aktivitas, dengan tujuan efisiensi itulah munculnya ide untuk merancang kunci pintu berbasis Internet of Thing yang harus kita terapkan di rumah-rumah apa lagi bila kita sebagai pemilik rumah merupakan orang yang sibuk beraktivitas di luar rumah, jadi kunci pintu berbasis Internet of Thing ini bakal sangat bermanfaat.

\section{METODE}

Adapun metode yang di gunakan adalah untuk menyajika dan kepuasan pengguna untuk menggunakan kunci pintu berbasis internet Of Things yang di kontrol menggunakan smartphone.

\subsection{METODE PROTOTYPE}

Metode Prototype adaIah metode pengembangan perangkat Iunak yang memungkinkan interaksi antara pengembang sistem dan pengguna sistem untuk mengatasi ketidakcocokan antara pengembang dan pengguna.

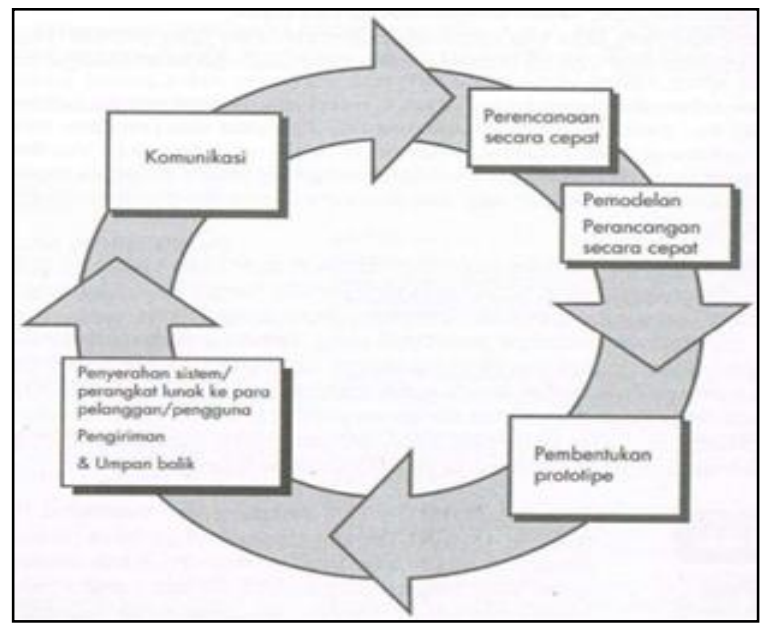

Gambar 1. Prototype Model 


\section{Journal of Computer and Information Systems Ampera}

Vol. 2, No. 1, January 2021 e-ISSN: 2775-2496

https://journal-computing.org/index.php/journal-cisa/index

\subsection{Prototype}

IdeaInya, prototype berfungsi sebagai mekanisme untuk mengidentifikasi spesifikasi kebutuhan perangkat lunak. Jika kita ingin mengembangkan prototype yang dapat digunakan, kita dapat menggunakan program yang sudah ada sebelumnya atau menerapkan penggunaan alat yang ada (misalnya, alat pembuat laporan [refort generator] atau aplikasi yang melakukan desain antarmuka [window manager]) , yang memungkinkan Anda untuk menggunakan program yang tersedia sangat mudah dan cepat. Fase fase umum dalam Prototyping adalah sebagai berikut:

1. Analisa Kebutuhan

Di tahap ini pengembang melakukan identifikasi software dan semua kebutuhan system yang akan di buat.

2. Membangun Prototyping

Membangun prototyping dengan membuat perancangan sementara yang berfokus pada penyajian kepada pelanggan (misalnya dengan membuat input dan format output.

3. Evaluasi Prototyping

Evaluasi ini dilakukan untuk mengetahui apakah prototyping sudah sesuai dengan harapan pelanggan.

4. Mengkodekan System

Pada tahap ini prototyping yang sudah di setujui akan diubah ke dalam Bahasa pemrograman.

5. Menguji sistem

Di tahap ini dilakukan untuk menguji system perangkat lunak yang sudah di buat.

6. Evaluasi Sistem

Perangkat lunak yang sudah siap jadi akan dievaluasi oleh pelanggan untuk mengetahui apakah system sesuai dengan yang di harapkan.

7. Menggunakan Sistem

Perangkat lunak yang sudah diuji dan di setujui oleh pelanggan siap digunakan.

\section{A. Diagram UML}

Pada fase pengembang, membuat rancangan perangkat lunak yang akan di buat berfokus pada penyajian kepada pengguna dan untuk melihat bagaimana sistem bekerja Ketika dieksekusi, biasa digambarkan dengan bantuan diagram UML, bentuk Activity diagram dan Use case diagram. Use 


\section{Journal of Computer and Information Systems Ampera}

Vol. 2, No. 1, January 2021 e-ISSN: 2775-2496

https://journal-computing.org/index.php/journal-cisa/index

Case Diagram ialah suatu representasi interaksi antara pengguna dengan sistem. Sehingga pembuatan use case diagram lebih dititik beratkan pada fungsionalitas yang ada pada sistem, dan siapa saja yang menggunakan fungs-fungsi tersebut[3].

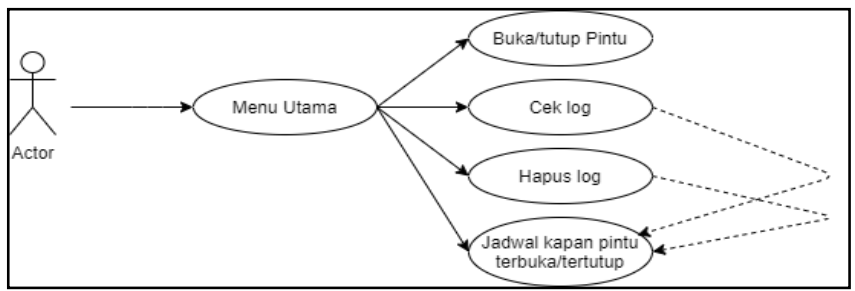

Gambar 2. Use Diagram

Activity Diagram adalah sebuah diagram yang menggambarkan sebuah alur kerja atau aliran control system. Diagram ini digunakan untuk melihat bagaimana system berkerja ketika dieksekusi. Activity diagram juga digunakan untuk menggambarkan interaksi antara beberapa use case[3].

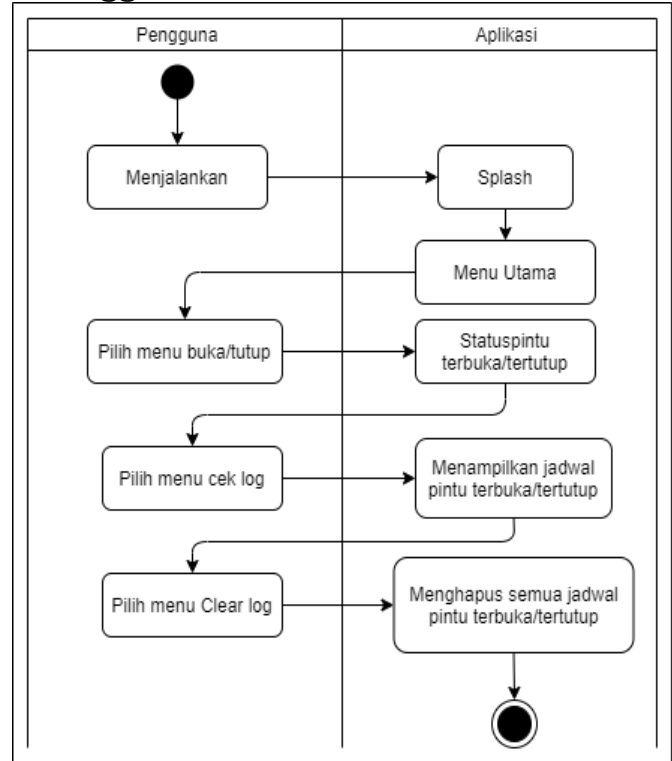

Gambar 3. Activity Diagram

\section{B. Menguji Sistem}

Pada fase ini di lakukan untuk menguji sistem perangkat lunak yang sudah di buat menggunakan black-box Testing. Black - Box Testing adalah teknik pengujian perangkat Iunak yang berfokus pada spesifikasi fungsional dari 


\section{Journal of Computer and Information Systems Ampera}

Vol. 2, No. 1, January 2021 e-ISSN: 2775-2496

https://journal-computing.org/index.php/journal-cisa/index

perangkat lunak, Blackbox Testing bekerja dengan mengabaikan struktur kontrol sehingga perhatiannya difokuskan pada informasi domain[4].

Tabel 1. Black Box Testing

\begin{tabular}{|c|c|c|c|c|}
\hline $\begin{array}{l}\text { Sekenario } \\
\text { pengujian }\end{array}$ & $\begin{array}{c}\text { Kasus } \\
\text { pengujian }\end{array}$ & $\begin{array}{l}\text { Hasil yang } \\
\text { diharapkan }\end{array}$ & $\begin{array}{c}\text { Hasil } \\
\text { pengujia } \\
\mathrm{n}\end{array}$ & $\underset{\mathrm{n}}{\text { kesimpula }}$ \\
\hline $\begin{array}{c}\text { Membuka/menutu } \\
\text { p pintu }\end{array}$ & $\begin{array}{c}\text { Klik } \\
\text { 'Tombol } \\
\text { buka/tutu } \\
\text { p' }\end{array}$ & $\begin{array}{c}\text { Pintu } \\
\text { terbuka/tertutu } \\
\mathrm{p}\end{array}$ & sesuai & normal \\
\hline $\begin{array}{l}\text { Melihat kapan } \\
\text { pintu } \\
\text { terbuka/tertutup }\end{array}$ & $\begin{array}{c}\text { Klik } \\
\text { 'Tombol } \\
\text { cek log' }\end{array}$ & $\begin{array}{c}\text { Menampilkan } \\
\text { jadwal kapan } \\
\text { pintu } \\
\text { terbuka/tertutu } \\
\text { p }\end{array}$ & sesuai & normal \\
\hline $\begin{array}{l}\text { Menghapus data } \\
\text { kapan pintu } \\
\text { terbuka/tertutup }\end{array}$ & $\begin{array}{c}\text { Klik } \\
\text { 'Tombol } \\
\text { clear log' }\end{array}$ & $\begin{array}{c}\text { Menghapus } \\
\text { jadwal kapan } \\
\text { pintu } \\
\text { terbuka/tertutu } \\
\text { p }\end{array}$ & sesuai & normal \\
\hline
\end{tabular}

\subsection{Internet of Things}

Internet of Things adalah sebuah konsep di mana semua perangkat dan layanan terhubung satu sama lain dengan mengumpulkan, bertukar, dan memproses data sehingga dapat disesuaikan secara dinamis. Dalam diskusi tentang "lingkungan rumah pintar" antara Internet of Things dan alat atau layanan tradisional, mereka diintegrasikan di rumah untuk meningkatkan kualitas hidup[5].

\subsection{Node MCU V3}

NodeMCU pada dasarnya adalah pengembangan modul WiFi ESP8266 berdasarkan firmware eLua. NodeMcu dilengkapi dengan port micro USB yang dapat digunakan untuk pemrograman dan power supply. Selain itu, NodeMCU 


\section{Journal of Computer and Information Systems Ampera}

Vol. 2, No. 1, January 2022 e-ISSN: 2775-2496

https://journal-computing.org/index.php/journal-cisa/index

dilengkapi dengan tombol yaitu tombol reset dan flash. NodeMCU menggunakan bahasa pemrograman Lua, yang merupakan paket modul WiFi ESP8266. Lua dan C memiliki logika dan struktur pemrograman yang sama, tetapi sintaksnya berbeda. Jika Anda menggunakan Lua, Anda dapat menggunakan alat Lua Loader dan Lua uploder. Selain bahasa Lua, NodeMCU juga mendukung software Arduino IDE dengan melakukan beberapa perubahan pada board manager Arduino IDE. Papan ini harus di-flash sebelum digunakan untuk mendukung alat yang akan digunakan. Jika Anda menggunakan Arduino IDE, harap gunakan firmware yang benar, yaitu firmware keluaran AiThinker yang mendukung ATCommand. Gunakan alat pengunggah firmware, gunakan firmware NodeMCU[6].

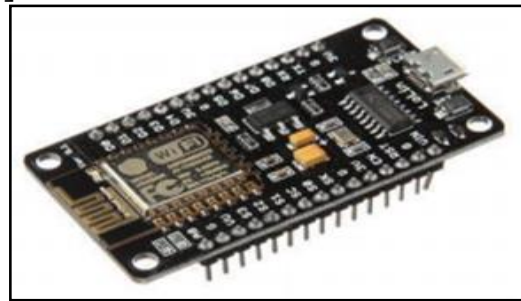

Gambar 4. Node MCU

\subsection{Kunci solenoid}

Selenoid adaIah Sebuah kumparan yang terbuat dari kawat panjang yang dililit rapat, yang dapat dianggap lebih panjang dari diameternya. Kunci elektromagnetik adalah kombinasi dari kunci dan katup solenoid, dan biasanya digunakan pada peralatan elektronik seperti kunci otomatis. Prinsip selenite ditemukan oleh seorang fisikawan Perancis bernama André Marie Ampere. Dalam rekayasa, istilah ini mengacu pada perangkat transduser yang mengubah energi menjadi gerakan linier. Ketika kumparan diberi energi, ia menghasilkan gaya elektromagnetik dan menarik besi di tengah kumparan dalam garis lurus[7].

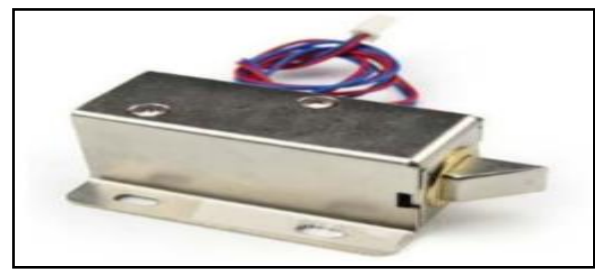

Gambar 5. Kunci Selenoid 


\section{Journal of Computer and Information Systems Ampera}

Vol. 2, No. 1, January 2021 e-ISSN: 2775-2496

https://journal-computing.org/index.php/journal-cisa/index

\subsection{Relay}

Relay adalah sakelar mekanis yang dikendalikan atau dikendalikan dengan metode elektronik (elektromagnetik)[8].

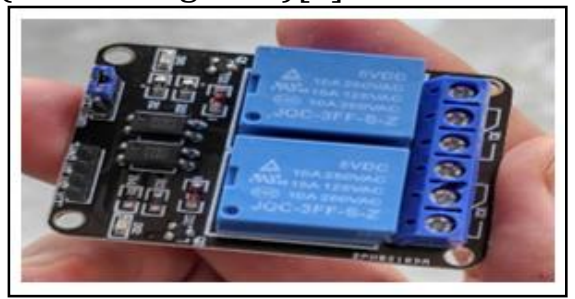

Gambar 6. Relay

\subsection{MIT App Inventor}

Mit app inventor adalah platform berbasis web tempat Anda dapat menggunakan aplikasi Android tanpa mengetahui cara mengkodekannya. Sistem ini telah dihentikan oleh Google, tetapi diluncurkan kembali oleh Google sebagai proyek open source dan saat ini dikelola oleh Massachusetts Institute of Technology (MIT).

\section{Hasil dan Pembahasan}

\subsection{Hasil Penelitian}

Setelah melakukan semua tahapan tahapan metode Prototype, dalam proses membangun sebuah perangkat lunak yang akan penulis gunakan untuk mengontrol alat kunci pintu berbasis IoT.

Penulis menarik kesimpulan metode Prototype, membuat pengembang dapat berkomunikasi bersama pengguna dengan lebih baik guna untuk menuntukan kebutuhan pengguna itu sendiri dan lebih menghemat waktu dalam pengembangan system.

\subsection{Hasil Aplikasi}

\subsubsection{Tampilan Icon}

Berikut ini adalah tampilan icon aplikasi saat di smartphone pengguna. Pengguna bisa melihatnya seperti gambar di bawah. 


\section{Journal of Computer and Information Systems Ampera}

Vol. 2, No. 1, January 2022 e-ISSN: 2775-2496

https://journal-computing.org/index.php/journal-cisa/index

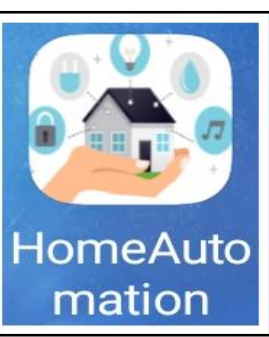

Gambar 7. Icon Aplikasi

\subsubsection{Tampilan Splash screen}

Tampilan halaman pembuka akan tampil saat aplikasi pertama kali dibuka sebelum ke tampilan halaman utama. Pada tampilan ini akan tambil beberapa detik, lalu akan berganti ke halaman utama.

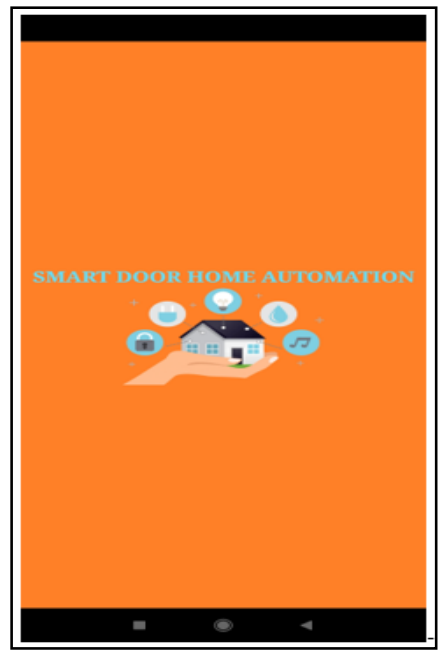

Gambar 8. Tampilan Splash Screen

\subsubsection{Tampilan Menu Utama}

Pada tampilan menu utama ini akan menampilkan menu - menu pada aplikasi ini dapat di klik untuk mengontrol alat kunci pintu dan menampilkan jadwal/status pintu terbuka atau tertutup. 


\section{Journal of Computer and Information Systems Ampera}

Vol. 2, No. 1, January 2021 e-ISSN: 2775-2496

https://journal-computing.org/index.php/journal-cisa/index

\subsection{Hasil Alat}

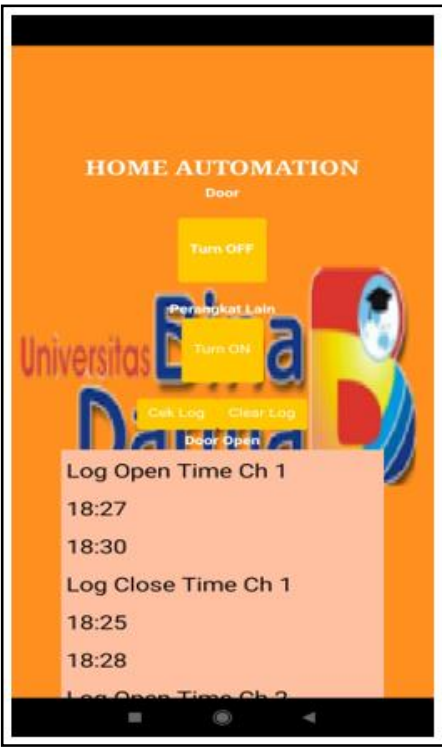

Gambar 9. Tampilan Menu Utama

Pada kali ini penulis akan menjelaskan hasil alat dan memberi pembahasan, alat yg di operasi kan harus terhubung ke jaringan internet atau wifi dahulu, Nodemcu juga sepenuhnya tidak dapat memberikan daya yang cukup untuk solenoid, karena daya output dari nodemcu hanya 3.3 volt sedangkan daya yang di butuhkan untuk membuka solenoid 12 volt maka di gunakan lah tambahan adapter 12 volt sebagai tambahan daya.

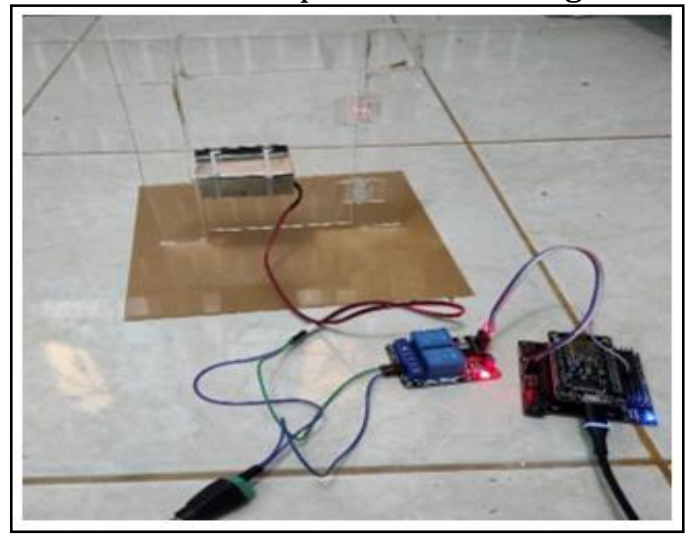

Gambar 10. Rangkaian Alat Saat Implementasi 


\section{Journal of Computer and Information Systems Ampera}

Vol. 2, No. 1, January 2022 e-ISSN: 2775-2496

https://journal-computing.org/index.php/journal-cisa/index

\subsection{Mekanisme Penggunaan Aplikasi dan Alat}

Aplikasi :

1. Pada smartphone tempat terinstal aplikasi harus terhubung dengan internet.

Alat:

1. Pastikan semua kabel jumper terhubung dengan benar.

2. NodeMCU harus terhubung ke internet atau wifi, dan tersambung ke listrik menggunakan adapter microusb untuk daya.

3. Modul jack dc tersambung ke listrik menggunakan adapter $12 \mathrm{v}$.

Berikut ini activity diagram penggunaan aplikasi Dan alat

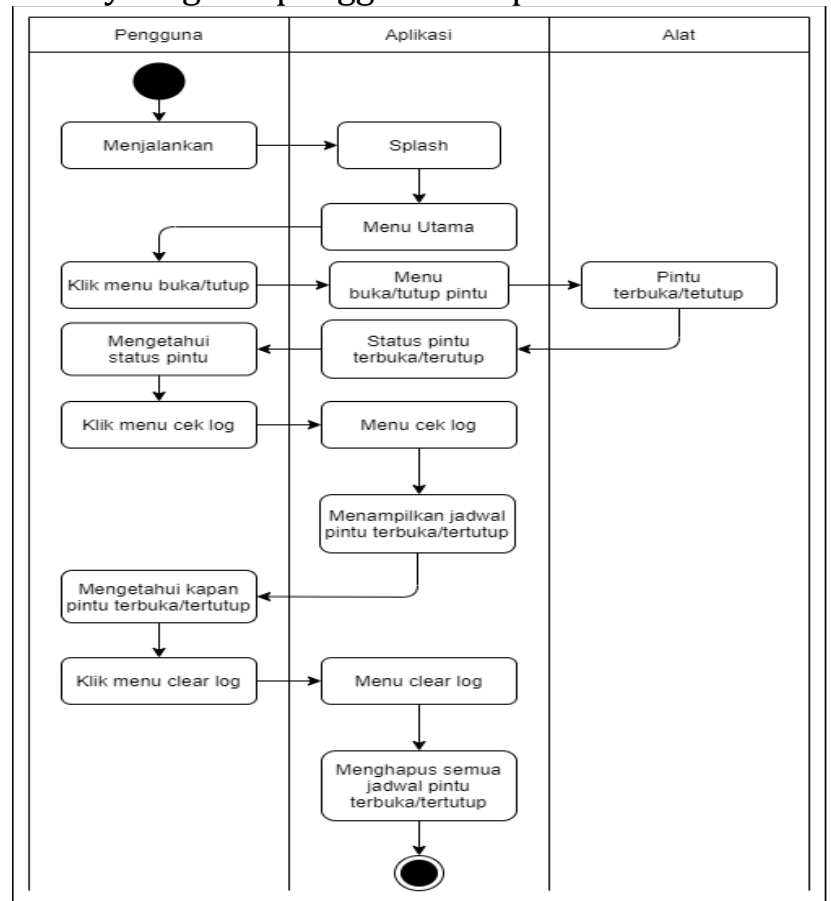

Gambar 11. Activity Diagram Mekanisme Penggunaan Aplikasi dan Alat 


\section{Journal of Computer and Information Systems Ampera}

Vol. 2, No. 1, January 2021 e-ISSN: 2775-2496

https://journal-computing.org/index.php/journal-cisa/index

\section{Kesimpulan}

Berdasarkan hasil dari implementasi dan pengujian yang dilakukan terhadap aplikasi dan alat yang telah di buat pada penelitian ini, maka dapat ditarik kesimpulan di antaranya sebagai berikut:

1. Metode prototype berhasil di terapkan, sehingga terbentuk sebuat aplikasi yang mampu digunakan dan di pahami dengan baik oleh pengguna untuk mengontrol alat.

2. Nodemcu sangat baik digunakan pada alat karena sudah memiliki modul wifi.

3. Penggunaan aplikasi untuk mengontol kunci pintu dan alat kunci pintu, ini dapat dirasakan praktis dan juga akan memberikan bantuan kepada pengguna terutama bagi orang yang sering terburu-buru saat bepergian sehingga lupa mengunci pintu.

\section{Daftar Pustaka}

[1] Z. B. Abilovani, W. Yahya, and F. A. Bakhtiar, "Implementasi Protokol MQTT Untuk Sistem Monitoring Perangkat IoT," J.

Pengemb. Teknol. Inf. dan Ilmu Komput. Univ. Brawijaya, vol. 2, no. 12, pp. 7521-7527, 2018.

[2] M. F. Dvali and M. D. Belonin, "Prospects for deep and ultradeep oil and gas deposits in u.s.s.r.," Int. Geol. Rev., vol. 8, no. 6, pp. 665675, 1966, doi: 10.1080/00206816609474324.

[3] I. G. T. Isa and G. P. Hartawan, "Perancangan Aplikasi Koperasi Simpan Pinjam Berbasis Web (Studi," J. Ilm. Ilmu Ekon., vol. 5, no. 10, pp. 139-151, 2017.

[4] T. S. Jaya, "Pengujian Aplikasi Dengan Metode Blackbox Testing Boundary Value Analysis (Studi Kasus: Kantor Digital Politeknik Negeri Lampung)," J. Inform. J. Pengemb. IT, vol. 3, no. 2, pp. 45-48, 2018.

[5] M. R. Hidayat, C. Christiono, and B. S. Sapudin, "IoT-Based Home Security System Design Using NodeMCU ESP8266, HC-SR501, PIR Sensor AND Smoke Detector Sensor," Kilat, vol. 7, no. 2, pp. 139148, 2018, doi: 10.33322/kilat.v7i2.357.

[6] U. S. Zsevril, “Universitas Sumatera Utara 4,” pp. 4-16, 2018.

[7] H. Shull, "The overhead headache," Science (80-. )., vol. 195, no. 4279, pp. 639Shull, H. (1977). The overhead headache. Scienc, 1977, doi: 10.1126/science.195.4279.639. 
Journal of Computer and Information Systems Ampera

Vol. 2, No. 1, January 2021 e-ISSN: 2775-2496

https://journal-computing.org/index.php/journal-cisa/index

[8] A. Satriadi, Wahyudi, and Y. Christiyono, "Perancangan Home Automation Berbasis NodeMCU," Transient, vol. 8, no. 1, pp. 64-71, 2019. 